\title{
Autoignition Behavior of an Ethanol-Methylcellulose Gel Droplet in a Hot Environment
}

\author{
Donggi Lee ${ }^{1}$, Jonghan Won ${ }^{1}$, Seung Wook Baek ${ }^{1, *}$ and Hyemin Kim ${ }^{2, *}$ \\ 1 Department of Aerospace Engineering, Korea Advanced Institute of Science and Technology (KAIST), \\ 291 Daehak-ro, Yuseong-gu, Daejeon 34141, Korea; kingdonggi@kaist.ac.kr (D.L.); \\ won1402@kaist.ac.kr (J.W.) \\ 2 Department of Aeronautical \& Mechanical Design Engineering, Korea National University of Transportation, \\ Daehak-ro 50, Chungju City 27469, Korea \\ * Correspondence: swbaek@kaist.ac.kr (S.W.B.); enok2695@ut.ac.kr (H.K.); \\ Tel.: +82-42-350-3714 (S.W.B.); +82-43-841-5838 (H.K.)
}

Received: 27 July 2018; Accepted: 17 August 2018; Published: 19 August 2018

\begin{abstract}
Autoignition of an ethanol-based gel droplet was experimentally investigated by adding $10 \mathrm{wt} \%$ of methylcellulose as gellant to liquid ethanol. Experimental studies of the ignition behavior of the gel droplet were found to be quite rare. The initial droplet diameter was $1.17 \pm 0.23 \mathrm{~mm}$. The gel droplet was suspended on a K-type thermocouple and its evaporation, ignition and combustion characteristics were evaluated and compared with pure ethanol at an ambient temperature of 600, 700 , and $800{ }^{\circ} \mathrm{C}$ under atmospheric pressure conditions. The gel droplet exhibited swelling and vapor jetting phenomena. Before ignition, a linear decrease in droplet diameter followed by a sudden increase was repeatedly observed, which was caused by evaporation and swelling processes, respectively. Major droplet swelling was detected just before the onset of ignition at all temperatures. But no further swelling was detected after ignition. For the gel droplet, the ignition delay accounted for $93 \%$ of the droplet lifetime at $600{ }^{\circ} \mathrm{C}$, and $88 \%$ at $700{ }^{\circ} \mathrm{C}$, but only $31 \%$ at $800{ }^{\circ} \mathrm{C}$. Its average burning rate was also evaluated for all temperatures. At $800^{\circ} \mathrm{C}$, the gellant layer no longer exerts any influence on the combustion of the gel droplet.
\end{abstract}

Keywords: autoignition; combustion; droplet; ethanol; gel propellant

\section{Introduction}

Gel propellants can be prepared by agitating liquid fuels with various gellants, depending on the properties required. Similar to liquid propellants, the gel propellants are subject to re-ignition, allowing thrust control when necessary. Such gel propellants exhibit an excellent stability, while allowing for easy handling and storage like solid propellants [1]. The gel propellants have been intensely studied since the 1940s, commencing by research on slurry fuels. Until the 1970s, gel propellants were studied as missile and rocket fuels, principally in the USA, but their combustion characteristics were less than theoretically expected [2]. However, after two successful flight tests by TRW in 1999 [3], further research recommenced in 2000.

Useful gel propellants must exhibit a shear thinning characteristic, which can be characterized rheologically [4-7]. Spray and atomization studies with a preparation of simulants were previously performed at the injector exit to determine if its performance was good enough compared with conventional liquid fuels [8-13]. Numerical studies have also been conducted to better understand the gel flow and droplet collisions [14,15]. Additional performance must be also evaluated in terms of ignition delay, the heat of combustion, and the burning rate; these can be explored both theoretically and experimentally. 
Kunin et al. [16] developed a theoretical model of a gel droplet combustion with organic gellant and numerically solved the model. Mishra et al. [17] reported that the burning rate constant decreased as the gellant concentration increased. Using an UDMH-RFNA gel containing metal particles, Gupta and Varma [18] found that the heat of combustion was lower than its theoretical value. Liu et al. [19] studied the combustion and microexplosion of UDMH gel experimentally, and found that the intensity of microexplosion decreased with pressure. Bar-or and Natan [20] studied the effects of pressure and ambient oxygen mass fraction on the burning rate of a kerosene gel. Arnold and Anderson [21] explored the rheological and combustion characteristics of a JP-8/silica gel, and reported that the $\mathrm{d}^{2}$-law used to analyze an evaporation of liquid fuel droplets could also be applied to a gel droplet behavior. Solomon et al. [22] confirmed that a gellant layer formation during droplet combustion was caused by a difference in the boiling points and viscosities of the gel propellant constituents. Negri and Ciezki [23] showed that aggregation occurred when a gel propellant containing aluminum particles based on jet A-1 was burned. It explained low combustion efficiency than expected. Recently, a research with optical access on gel combustion chamber was also carried out, which made detailed analysis possible [24].

The combustion of a single gel droplet lacking metal particles can be divided into four stages, of which the first is heat-up, similar to the combustion of a typical liquid fuel droplet. In the second stage, a film or layer of gellant is formed, followed by swelling or a micro-explosion as the fuel bubble inside the droplet expands. Thereafter, the gellant layer thickens and bursts in the third stage, triggering fuel vapor jetting and rupture of the flame structure. At the stage four, the gellant begins to burn, either exhibiting a uniform regression of the droplet or other very complicated behavior depending on the type of gelling agent used $[17,22]$.

Previously, most of researchers used to observe combustion behavior characteristics after an external ignition of the gel droplet. However, an autoignition characteristic of the gel droplet was rarely investigated. Therefore, in this study the autoignition characteristic of the gel droplet is to be observed and investigated. Autoignition occurs if fuel vapor is mixed with an appropriate concentration of oxidizer, and the temperature around the droplet is higher than the autoignition temperature. Regarding the autoignition in this study, the gel droplet is to be observed throughout the time interval from evaporation to combustion, which allows the autoignition behavior of the gel droplet to be better understood.

\section{Materials and Methods}

\subsection{Ethanol Gel Preparation}

Ethanol (CAS number 64-17-5; Sigma-Aldrich, St. Louis, MO, USA) was selected as a parent fuel because it is minimally toxic and easy to handle. Its autoignition temperature is $363^{\circ} \mathrm{C}$ according to the manufacturer. Methylcellulose (CAS number: 9004-67-5; Sigma-Aldrich) served as the organic gellant since it is an eco-friendly material. The solvent was distilled water because the gelation mechanism of methylcellulose is cross link of hydrophobic units of methylcellulose. Gellant levels of 9-11 wt \% were used to make gels with excellent rheological properties in preliminary tests. Ethanol gel with $10 \mathrm{wt} \%$ of methylcellulose was selected for further study as shown in Figure 1, since it exhibits a shear thinning behavior. Its compositions are listed in Table 1 . The calorific value measured in an oxygen bomb calorimeter (1341 Plain Jacket Bomb Calorimeter and 6772 Calorimetric Thermometer, Parr Instrument Company, Moline, IL, USA) was $27.57 \mathrm{MJ} / \mathrm{kg}$ which is about $93 \%$ of the calorific value of pure liquid ethanol. 


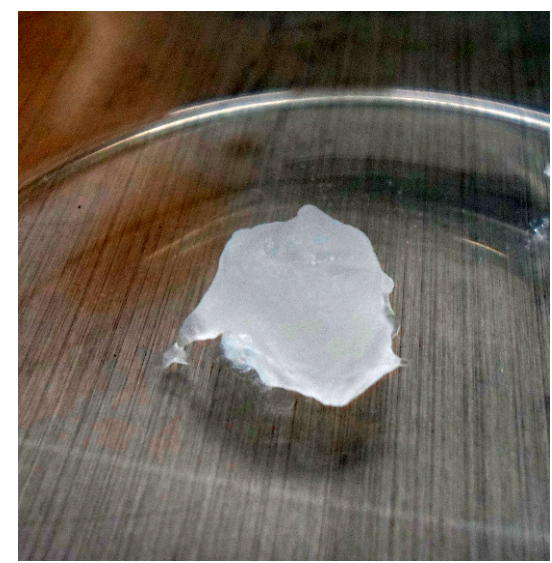

Figure 1. Ethanol gel with $10 \mathrm{wt} \%$ of methylcellulose.

Table 1. Composition of ethanol gel with $10 \mathrm{wt} \%$ of methylcellulose.

\begin{tabular}{cccc}
\hline Component & Ethanol & Methylcellulose & Water \\
\hline Concentration $(w t \%)$ & 75 & 10 & 15 \\
\hline
\end{tabular}

\subsection{Combustion Chamber}

A combustion chamber was used to study an autoignition phenomenon of the ethanol gel and its schematic is shown in Figure 2. The electric furnace can be moved vertically to rapidly expose a gel droplet to high temperature environment, which was controlled within $5{ }^{\circ} \mathrm{C}$ using a proportional-integral-derivative (PID) device.

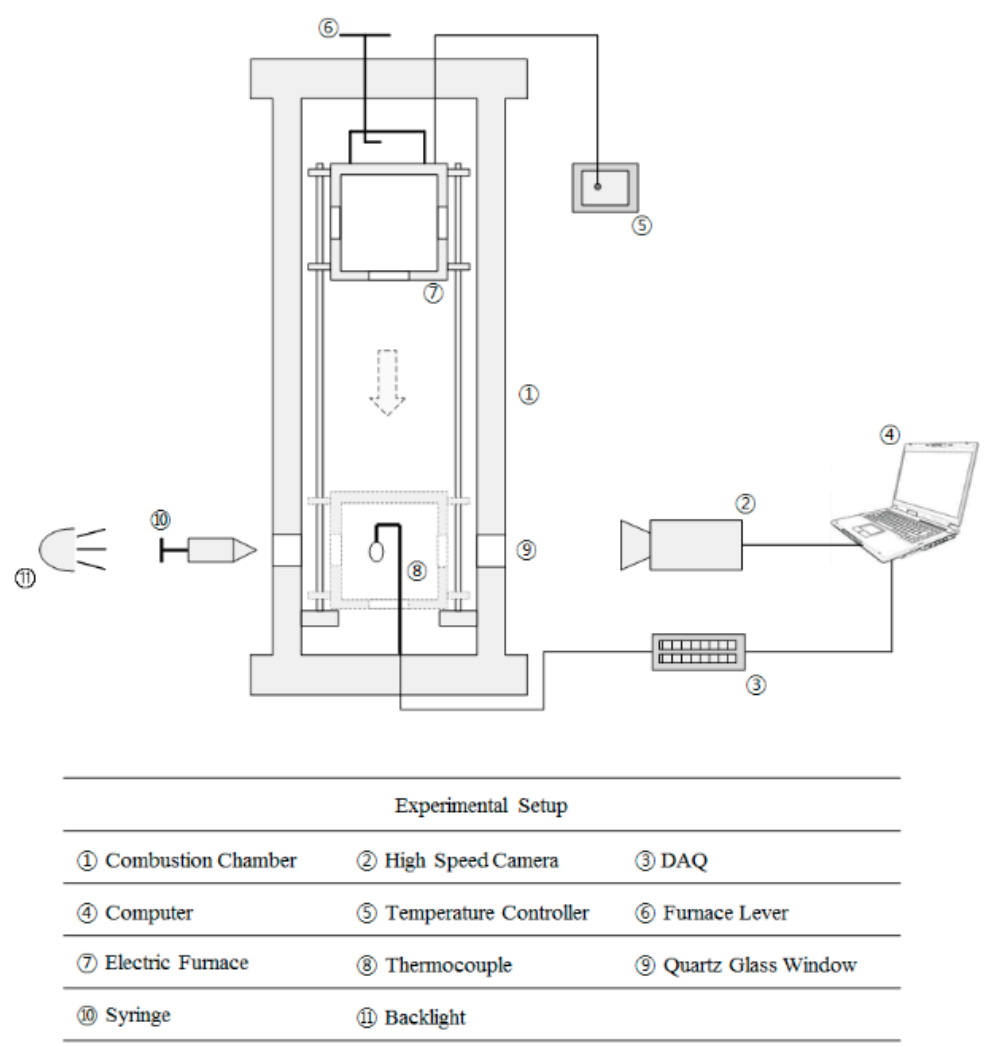

Figure 2. Schematic diagram of experimental setup. 
The gel droplet was suspended on a K-type thermocouple using a 23-gauge syringe. It allowed a measurement of droplet internal temperature. In most of the droplet researches, droplets were suspended on quartz fibers just as the previous researchers who used this experimental apparatus. Meanwhile, Harada et al. [25] studied the effect of thermocouple diameter when droplet suspended both numerically and experimentally. According to his research, in case of $50 \mu \mathrm{m}$ wire, which is same as this study, maximum temperature error was less than $10 \%$ with good agreement of experiment and numerical simulation. Also Khan et al. [26] reported that the temperature reaches to the $98 \%$ of the set value in less than $50 \mathrm{~ms}$ for the tests below $1.0 \mathrm{MPa}$. Such a chamber has been used by previous researches and more details are available therein [27-29].

\subsection{High-Speed Camera}

A high-speed camera (X-stream 3, Integrated Design Tools, Pasadena, CA, USA) was used to observe a transient behavior of the gel droplet. Two hundred high-resolution color images per second were acquired for each experiment, from which a variation of the droplet diameter was estimated using an in-house visual basic software. This process has been used by many researchers [27-29]. Gel configuration is not completely spherical, therefore the droplet image boundary was converted to the effective spherical diameter of the same surface area [30].

\subsection{Ignition Delay and Average Burning Rate}

Once the gel droplet is exposed to a high temperature environment, it begins to evaporate while being heated up and the fuel vapor generated around the droplet starts to diffuse radially. When the vapor mixes with air and it reaches the ignition temperature, the mixture is ignited [26]. The time elapsed from an exposure of the gel droplet to high temperature to the onset of ignition is termed as the ignition delay [31], which usually consists of both physical and chemical delays. The physical delay accounts for the period from droplet heating to evaporation and a formation of a combustible mixture. The chemical delay takes account of the time required for the mixture to overcome the activation energy, finally reaching an onset of ignition [32]. In this study, a diffusion controlled flame would be expected so that the physical delay is to be predominant. In the following, the time from flame ignition to its extinction is termed as the flame lifetime, while the time from initial droplet exposure to high temperature to flame extinction is referred to as the droplet lifetime which includes the ignition delay and flame lifetime.

As an ethanol gel is a multi-component fuel, very active and unexpected changes are to be expected during combustion, unlike the case with single liquid fuel droplets. Thus, the concept of an average burning rate is introduced to study the droplet behavior exhibiting an active micro-explosion as for the emulsion droplet combustion [33]:

$$
\overline{K_{b}}=\left(D_{i g}^{2}-D_{\text {ext }}^{2}\right) / \Delta t_{1}
$$

where $D_{i g}$ is the droplet diameter at the onset of ignition, and $D_{\text {ext }}$ that at the time of flame extinction; $t_{1}$ is the time elapsed between ignition and extinction.

\subsection{Experimental Condition}

Experiments were performed under an atmospheric pressure condition at the ambient temperature of 600,700 , and $800{ }^{\circ} \mathrm{C}$. In previous studies, it was not known how the surrounding temperature affected the ignition and combustion of the gel droplet because of the use of external ignition source. Therefore, we will focus on the change of ignition delay and average burning rate to study the effect of temperature quantitatively. In addition, pure ethanol droplet was compared with gel droplet under the same conditions. This will clearly show the autoignition characteristic of gel droplet. 


\section{Results and Discussion}

\subsection{Ignition and Combustion Behavior of Ethanol Gel}

The gel droplet diameter was $1.17 \pm 0.23 \mathrm{~mm}$ and the standard deviation $0.11 \mathrm{~mm}$. The experiment was repeated seven times for each case. Figures 3-5 show the autoignition and combustion process of the ethanol gel droplet with $10 \mathrm{wt} \%$ of methylcellulose. As shown in the figures, the gel droplet was ignited at all the temperatures of 600,700 , and $800{ }^{\circ} \mathrm{C}$, while leaving no residues. Before ignition, the droplet volumes generally decreased, but sometimes, a sudden expansion (swelling) was observed as in Figures $3 \mathrm{~b}$ and $4 \mathrm{~b}$ which is caused by gas expansion trapped in the gellant layer [22]. At $600{ }^{\circ} \mathrm{C}$, when the gel droplet was exposed to high temperature, the ethanol and water contents are evaporated and the gellant layer begins to form. After the onset of ignition as in Figure $3 \mathrm{~d}$, the droplet size rapidly decreased while burning without leaving any residue. A similar behavior was observed for the gel droplet at $700{ }^{\circ} \mathrm{C}$, but both ignition as shown in Figure $4 \mathrm{e}$ and combustion proceeded faster than at $600{ }^{\circ} \mathrm{C}$.

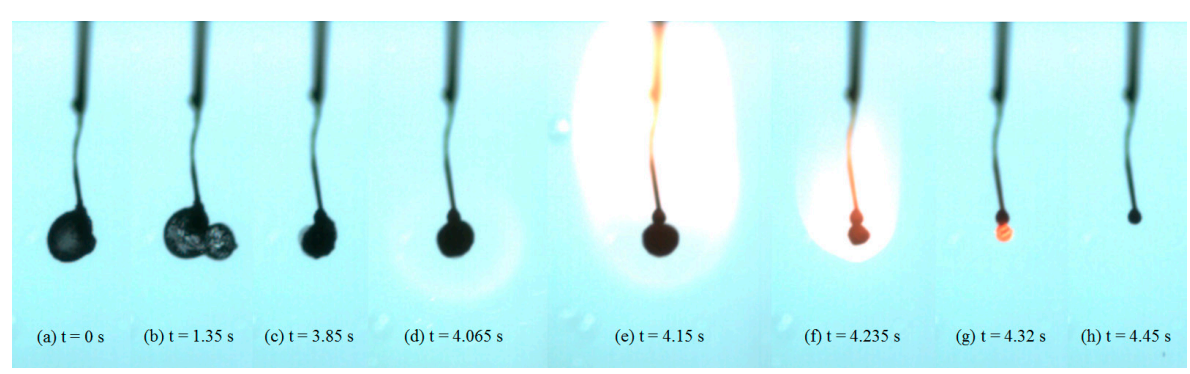

Figure 3. Ignition and combustion behavior of ethanol gel at $600{ }^{\circ} \mathrm{C}$.

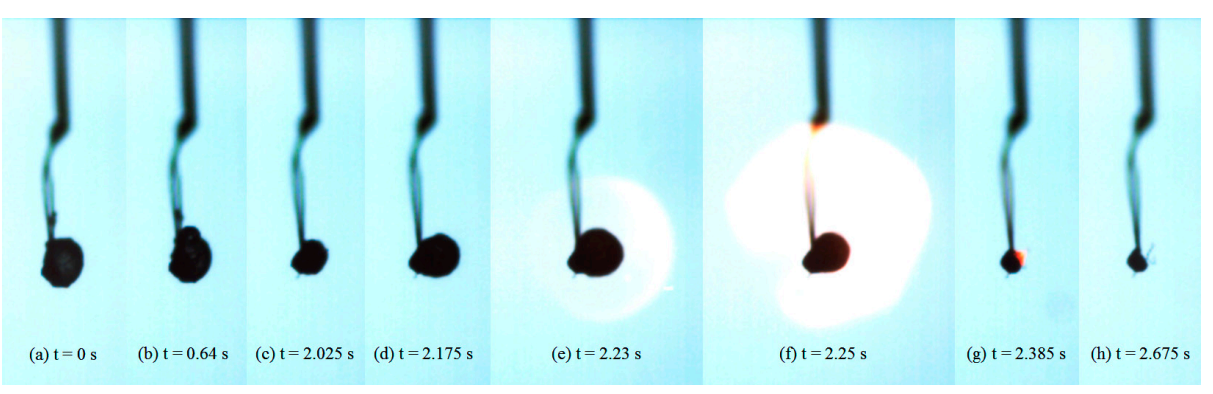

Figure 4. Ignition and combustion behavior of ethanol gel at $700{ }^{\circ} \mathrm{C}$.

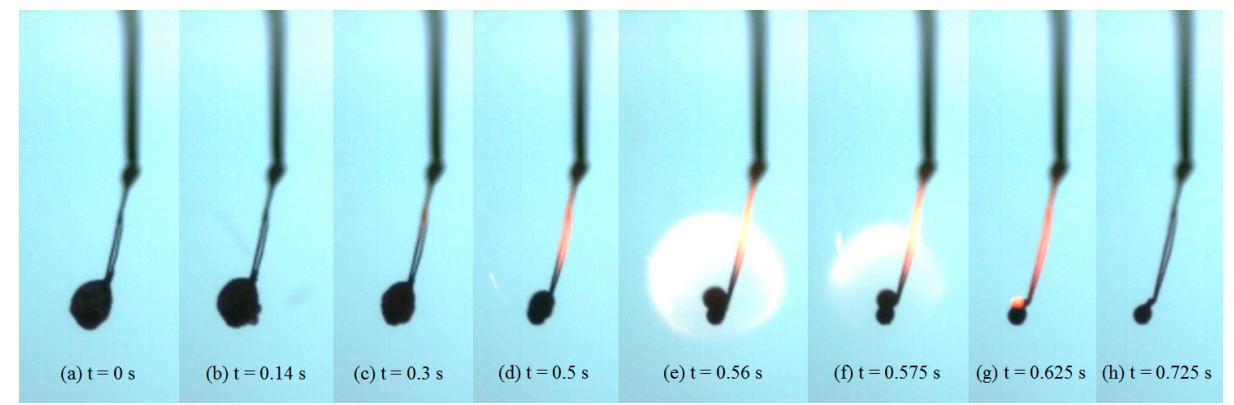

Figure 5. Ignition and combustion behavior of ethanol gel at $800{ }^{\circ} \mathrm{C}$.

At $800{ }^{\circ} \mathrm{C}$, the ignition occurred much faster as in Figure $5 \mathrm{c}$ which was then followed by a sharp decrease in size and complete gellant combustion. At this time, the droplet surface became reddish as in Figure $5 \mathrm{~g}$ while no flame was apparent, but combustion was nonetheless completed, which is 
attributable to the combustion of the gellant residue. The similar combustion behavior of remaining gellant is also observed for the case with 600 and $700{ }^{\circ} \mathrm{C}$ as in Figures $3 \mathrm{~g}$ and $4 \mathrm{~g}$. Generally vapor jetting can be observed at all temperatures and is particularly noticeable just after swelling. When swelling occurs due to the expansion of the gas inside of droplet, the thickness of gellant layer becomes thinner as the volume becomes larger. If tiny holes are created on the gellant layer, the vapor escapes to the outside. Figure 6 shows an instantaneous flame through the jetted vapor, which was observed once in a while. In the left-hand side image, the arrow points to a rupture in the gellant layer. Instantly, hot ethanol vapor jetted out of the gellant layer through dashed arrow and ignited quickly in contact with oxygen, forming an immediate flame as shown in the right-hand side image.

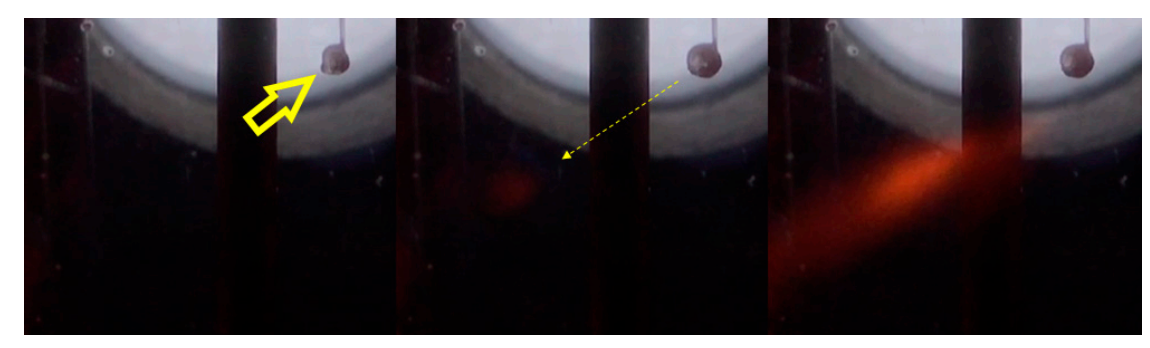

Figure 6. Flame on vapor jetting of ethanol gel droplet.

According to the four-stage combustion of the gel droplet from previous study, which was introduced in chapter 1 , there was flame from the beginning of heating up process (stage I) since it used an external ignition source. However, in this experiment, those occurred during heating up and evaporation process without flame. These differences make direct comparison difficult, but still combustion process of ethanol gel droplet can also be divided to four stages. Heating up process for stage I is (a)-(b) in the Figures 3-5, where ethanol and water begin to evaporate. Stage II can be (b)-(c) in the Figures 3-5, which includes formation of gellant layer followed by swelling and decrease of size. Gellant layer thickens and bursts in stage III, it leads to vapor jetting and ignition of the droplet that are shown at (d)-(f) in the Figures 3-5. Finally, at (g)-(h) in the Figures 3-5, the rest gellant burns exhibiting a uniform regression, which is stage IV.

\subsection{Droplet Diameter Variation for Various Ambient Temperatures}

Figure 7 shows the pure ethanol droplet size change at each temperature. At $600{ }^{\circ} \mathrm{C}$, the pure ethanol droplet size deceased very steadily, but it was not ignited, presumably because all the heat feedback to the pure ethanol droplet might be used for its evaporation.

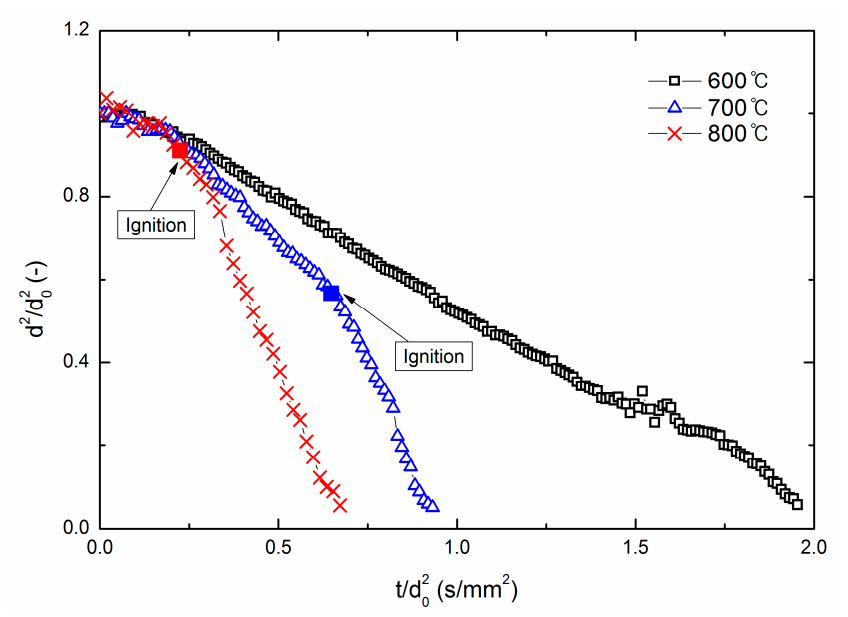

Figure 7. Pure ethanol droplet size variation for various ambient temperatures. 
For the case with the ethanol gel droplet, however, the evaporation might be hindered by the surface gellant layer, while the ethanol vapor inside it was heated. On the other hand, at $700{ }^{\circ} \mathrm{C}$, the diameter reduced almost linearly during the evaporation process, and the slope changed after ignition. At $800{ }^{\circ} \mathrm{C}$, there was slight perturbation during the initial heating up period, but after the ignition, the diameter decreased almost uniformly. Droplet lifetime shortened as the ambient temperature increased.

Figure 8 shows the transient ethanol gel droplet size and internal temperature variations for ambient temperatures of 600,700 , and $800{ }^{\circ} \mathrm{C}$. The droplet size decrease due to evaporation and then its rapid increase due to swelling were repeatedly observed. This droplet behavior, however, was not observed for $800^{\circ} \mathrm{C}$. Just at an onset of ignition, a sudden major swelling occurrence was apparent for all the temperatures. At this time, it is apparent that the fuel vapor released through the ruptured gellant layer is ignited.

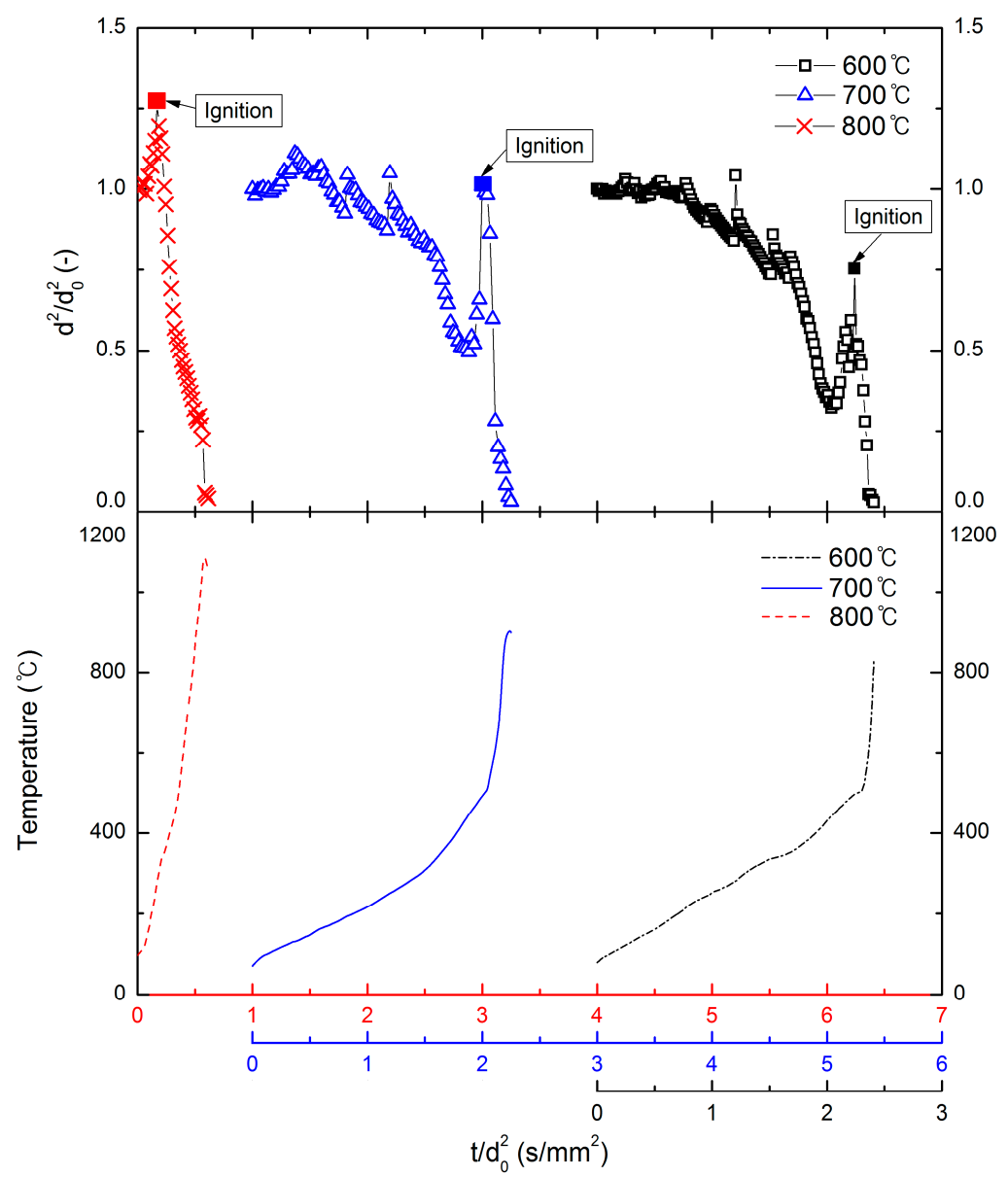

Figure 8. Ethanol gel droplet size and temperature variations for various ambient temperatures.

For the cases with 600 and $700{ }^{\circ} \mathrm{C}$, when there occurs an onset of ignition as marked in Figure 8, the flame shape is observed to be spherical as shown in Figures $4 \mathrm{~d}$ and $5 \mathrm{e}$, respectively. The ignition is then followed by a rapid increase in the gel droplet core temperature as in Figure 8. Since the internal gel droplet temperature exceeded the ethanol autoignition temperature, the fuel vapor escaping through the gellant layer would be easy to ignite as soon as it formed a combustible mixture with oxygen. On the other hand, this rapid increase behavior in the gel droplet temperature was not observed for the case with $800{ }^{\circ} \mathrm{C}$ as shown in Figure 8. In this case, no active combustion was evident because the gel droplet temperature at the onset of ignition was lower than the autoignition temperature. Consequently, a spherical flame was developed and observed in Figure 6e, which was 
much later than the onset of ignition as in Figure $6 c$, i.e., only after the internal droplet temperature had risen sufficiently.

After ignition, the gel droplet diameter decreased rapidly without further swelling, which is different from what is seen when an external ignition source is employed. Previous studies [17,21,22,34] described the droplet swelling even during combustion. However, the droplet swelling during combustion after the ignition was not observed in this study, presumably because the combustion commenced only after a sufficient amount of ethanol evaporated. Particularly, during the major swelling that is evident just at the onset of ignition, the fuel vapor inside the droplet might be fully released, which made no further swelling.

\subsection{IgnitionDdelay and Average Burning Rate}

Figure 9 shows the ignition delay and flame lifetime of pure liquid ethanol and the ethanol gel with $10 \mathrm{wt} \%$ of methylcellulose. Their corresponding average burning rate is listed in Table 2.

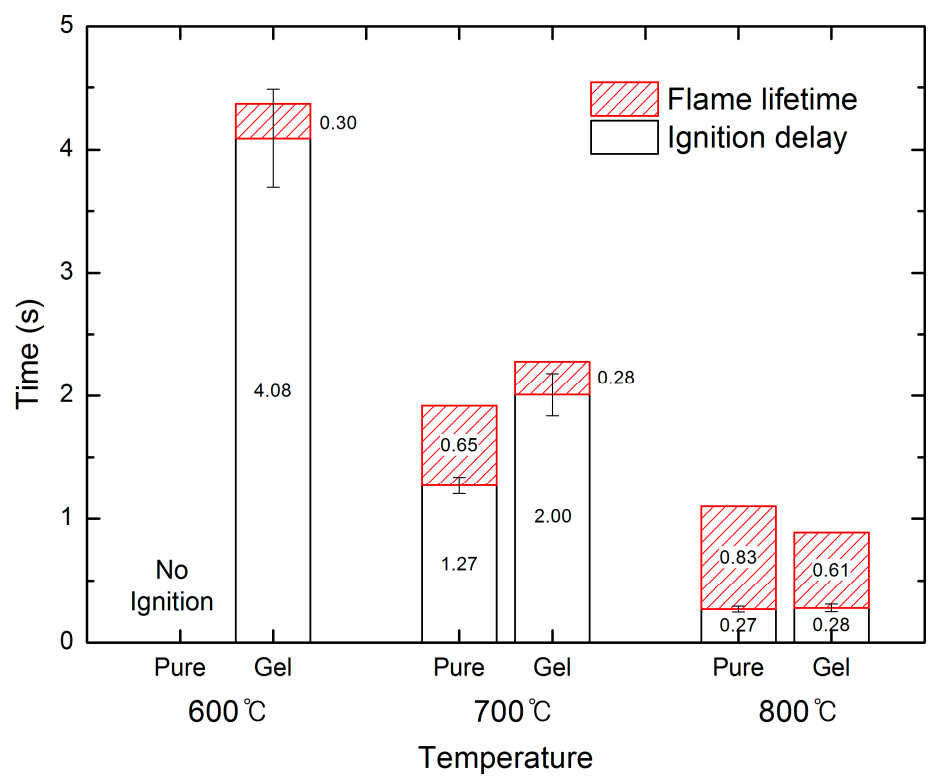

Figure 9. Ignition delay and flame lifetime of ethanol gel.

Table 2. Average burning rate of ethanol gel for various conditions.

\begin{tabular}{ccc}
\hline \multirow{2}{*}{ Temperature $\left({ }^{\circ} \mathrm{C}\right)$} & \multicolumn{2}{c}{ Average Burning Rate $\left(\mathrm{mm}^{2} / \mathbf{s}\right)$} \\
\cline { 2 - 3 } & Pure Ethanol & Ethanol Gel \\
\hline 600 & - & 2.26 \\
700 & 0.84 & 3.33 \\
800 & 1.09 & 1.84 \\
\hline
\end{tabular}

The ignition delay of the ethanol gel was found to be longer than that of pure ethanol at $700{ }^{\circ} \mathrm{C}$ as observed in Figure 9, because the gellant layer might inhibit its efficient evaporation. At $800{ }^{\circ} \mathrm{C}$, the ignition delay of the pure ethanol and the ethanol gel was very similar and it was much shorter than that at 600 and $700{ }^{\circ} \mathrm{C}$.

The average burning rate increased as the temperature increased, as seen at 700 and $800{ }^{\circ} \mathrm{C}$ for pure ethanol and at 600 and $700{ }^{\circ} \mathrm{C}$ for the ethanol gel. Also the burning rate of pure ethanol were lower than that of gel. At $700{ }^{\circ} \mathrm{C}$, the ignition delay was shorter than the gel case, thus larger droplet was burned and lower value was evaluated. At $800^{\circ} \mathrm{C}$, the ignition delay was similar with the gel case. However, unlike ethanol, which maintained almost constant internal temperature, the internal 
temperature of gel was getting higher since it was mixture. This led to shorter flame lifetime and higher burning rate in gel case. On the other hand, the ethanol gel burning rate decreased at $800{ }^{\circ} \mathrm{C}$ because the flame lifetime was relatively longer than at the other temperatures. This longer flame lifetime results from the fact that more ethanol gel or liquid was left due to shorter ignition delay for $800{ }^{\circ} \mathrm{C}$. However, this should be understood from the point of view that the ignition delay of 600 and $700{ }^{\circ} \mathrm{C}$ were very long, and those at $800{ }^{\circ} \mathrm{C}$ were a special case. Considering the results of both ignition delay and burning rate, the effect of gellant layer, which inhibited evaporation at 600 and $700{ }^{\circ} \mathrm{C}$, was significantly reduced at $800{ }^{\circ} \mathrm{C}$. At $800{ }^{\circ} \mathrm{C}$, it was ignited much earlier than the other cases, thus it could be presumed that the temperature reached above boiling point of ethanol, water, and gellant before the gellant layer thickened. As a result, the gellant layer didn't have chance to inhibit evaporation, so all constituents participated in combustion.

The average burning rate listed in Table 2 is higher than $0.83 \mathrm{~mm}^{2} / \mathrm{s}$ which is the burning rate of ethanol at atmospheric pressure as reported by Lee and Law [35] and Botero et al. [36]. This is because in this study a high-temperature environment was continuously maintained during combustion so that the droplet continued to take heat from the hot environment.

\section{Conclusions}

In this study an ethanol gel droplet was constructed by mixing $10 \mathrm{wt} \%$ of methylcellulose and tested at an ambient temperature condition of 600,700 , and $800{ }^{\circ} \mathrm{C}$ to understand its evaporation and combustion characteristics. The gel droplet was ignited at all temperatures while no residue was left. Swelling and fuel vapor jetting due to gellant layer were apparently observed during the evaporation process of gel droplet. Major droplet swelling was detected at all temperatures, which was regarded as the onset of ignition in this study. At 600 and $700{ }^{\circ} \mathrm{C}$, a linear decrease in droplet diameter followed by a sudden increase was repeatedly detected, which was caused by repeated evaporation and swelling processes. At $800{ }^{\circ} \mathrm{C}$, the gel droplet was quickly ignited and burnt in a weak flame, which later developed into a spherical flame. No further swelling was noted after ignition.

The autoignition delay of the ethanol gel was compared to that of pure ethanol. For the gel, the ignition delay accounted for $93 \%$ of droplet lifetime at $600{ }^{\circ} \mathrm{C}$ and $88 \%$ at $700{ }^{\circ} \mathrm{C}$, but at $800{ }^{\circ} \mathrm{C}$, it fell to $31 \%$. Pure ethanol was not ignited at $600^{\circ} \mathrm{C}$, whereas its ignition delay decreased and its average burning rate increased as the ambient temperature increased from 700 to $800{ }^{\circ} \mathrm{C}$. The gellant layer obstructed mass transfer, thereby prolonging the ignition delay of the gel droplet and triggering the swelling phenomenon.

The ethanol gel at $700{ }^{\circ} \mathrm{C}$ showed the largest average burning rate followed by $600{ }^{\circ} \mathrm{C}$ and $800{ }^{\circ} \mathrm{C}$. It increased as the temperature increased in case of pure ethanol. The smallest value of ignition delay and average burning rate were at $800{ }^{\circ} \mathrm{C}$, which indicates that the gellant layer no longer exerts any influence on the combustion of the gel droplet from $800{ }^{\circ} \mathrm{C}$.

Author Contributions: D.L. and J.W. conceived and designed the experiments; D.L. and J.W. performed the experiments; D.L. analyzed the data; and D.L., S.W.B., H.K. wrote the paper. All the authors read and confirmed the final manuscript.

Funding: This research was funded by the National Research Foundation of Korea (NRF) grant funded by the Korea government (MEST) (No. 2014R1A2A2A01007347).

Conflicts of Interest: The authors declare no conflict of interest.

\section{References}

1. Teipel, U.; Forter-Barth, U. Rheological behavior of nitromethane gelled with nanoparticles. J. Propul. Power 2005, 21, 40-43. [CrossRef]

2. Natan, B.; Rahimi, S. The status of gel propellants in year 2000. Int. J. Energ. Mater. Chem. Propul. 2002, 5, 172-194. [CrossRef] 
3. Hodge, K.; Crofoot, T.; Nelson, S. Gelled propellants for tactical missile applications. In Proceedings of the 35th AIAA/ASME/SAE/ASEE Joint Propulsion Conference \& Exhibit, Los Angeles, CA, USA, 20-23 June 1999; AIAA-99-2976.

4. Rapp, D.; Zurawski, R. Characterization of aluminum/rp-1 gel propellant properties. In Proceedings of the 24th AIAA/ASME/SAE/ASEE Joint Propulsion Conference, Boston, MA, USA, 11-13 July 1988; AIAA-88-2821.

5. Varma, M.; Gupta, B.; Pandey, M. Formulation \& storage studies on hydrazine-based gelled propellants. Def. Sci. J. 1996, 46, 435-442.

6. Santos, P.; Carignano, M.; Campanella, O. Qualitative study of thixotropy in gelled hydrocarbon fuels. Eng. Lett. 2011, 19, 13-19.

7. Dennis, J.D.; Kubal, T.D.; Campanella, O.; Son, S.F.; Pourpoint, T.L. Rheological characterization of monomethylhydrazine gels. J. Propul. Power 2013, 29, 313-320. [CrossRef]

8. Mansour, A.; Chigier, N. Air-blast atomization of non-newtonian liquids. J. Non-Newtonian Fluid Mech. 1995, 58, 161-194. [CrossRef]

9. Lee, I.; Koo, J. Break-up characteristics of gelled propellant simulants with various gelling agent contents. J. Therm. Sci. 2010, 19, 545-552. [CrossRef]

10. Chojnacki, K.; Feikema, D. Atomization studies of gelled liquids. In Proceedings of the 30th AIAA/ASME/ SAE/ASEE Joint Propulsion Conference, Indianapolis, IN, USA, 27-29 June 1994; AIAA-94-2773.

11. Heislbetz, B.; Madlener, K.; Ciezki, H. Breakup characteristics of a newtonian liquid sheet formed by a doublet impinging jet injector. In Proceedings of the 43rd AIAA/ASME/SAE/ASEE Joint Propulsion Conference \& Exhibit, Cincinnati, OH, USA, 8-11 July 2007; AIAA-2007-5694.

12. Green, J.; Rapp, D.; Roncace, J. Flow visualization of a rocket injector spray using gelled propellant simulants. In Proceedings of the 27th AIAA/ASME/SAE/ASEE Joint Propulsion Conference, Sacramento, CA, USA, 24-27 June 1991; AIAA-91-2198.

13. Mallory, J.; DeFini, S.J.; Sojka, P. Formulation of gelled propellant simulants. In Proceedings of the 46th AIAA/ASME/SAE/ASEE Joint Propulsion Conference \& Exhibit, Nashville, TN, USA, 25-28 July 2010; AIAA-2010-7142.

14. Rahimi, S.; Natan, B. Numerical solution of the flow of power-law gel propellants in converging injectors. Propellants Explos. Pyrotech. 2000, 25, 203-212. [CrossRef]

15. Liu, Z.; Wu, J.; Zhen, H.; Hu, X. Numerical simulation on head-on binary collision of gel propellant droplets. Energies 2013, 6, 204-219. [CrossRef]

16. Kunin, A.; Natan, B.; Greenberg, J.B. Theoretical model of the transient combustion of organic-gellant-based gel fuel droplets. J. Propul. Power 2010, 26, 765-771. [CrossRef]

17. Mishra, D.P.; Patyal, A.; Padhwal, M. Effects of gellant concentration on the burning and flame structure of organic gel propellant droplets. Fuel 2011, 90, 1805-1810. [CrossRef]

18. Gupta, B.L.; Varma, M. Ignition and combustion studies on metallized UDMH-RFNA bipropellant system. Indian J. Eng. Mater. Sci. 1999, 6, 13-21.

19. Liu, Z.; Hu, X.; He, Z.; Wu, J. Experimental study on the combustion and microexplosion of freely falling gelled unsymmetrical dimethylhydrazine (UDMH) fuel droplets. Energies 2012, 5, 3126-3136. [CrossRef]

20. Bar-or, D.; Natan, B. The effect of ambient conditions on the burning rate of gel fuel droplets. Propellants Explos. Pyrotech. 2013, 38, 199-203. [CrossRef]

21. Arnold, R.; Anderson, W. Droplet burning of JP-8/silica gels. In Proceedings of the 48th AIAA Aerospace Sciences Meeting Including the New Horizons Forum and Aerospace Exposition, Orlando, FL, USA, 4-7 January 2010; AIAA-2010-421.

22. Solomon, Y.; Natan, B.; Cohen, Y. Combustion of gel fuels based on organic gellants. Combust. Flame 2009, 156, 261-268. [CrossRef]

23. Negri, M.; Ciezki, H.K. Combustion of gelled propellants containing microsized and nanosized aluminum particles. J. Propul. Power 2014, 31, 400-407. [CrossRef]

24. Kirchberger, C.; Ciezki, H.; Kröger, P. Realization and run-in of a gel combustion chamber with optical access. In Proceedings of the 7th European conference for Aeronautics and Space Sciences(EUCASS2017), Milan, Italy, 3-6 July 2017. 
25. Harada, T.; Watanabe, H.; Suzuki, Y.; Kamata, H.; Matsushita, Y.; Aoki, H.; Miura, T. A numerical investigation of evaporation characteristics of a fuel droplet suspended from a thermocouple. Int J. Heat Mass Transf. 2011, 54, 649-655. [CrossRef]

26. Khan, Q.S.; Baek, S.W.; Ghassemi, H. On the autoignition and combustion characteristics of kerosene droplets at elevated pressure and temperature. Combust. Sci. Technol. 2007, 179, 2437-2451. [CrossRef]

27. Ghassemi, H.; Baek, S.W.; Khan, Q.S. Experimental study on binary droplet evaporation at elevated pressures and temperatures. Combust. Sci. Technol. 2006, 178, 1031-1053. [CrossRef]

28. Javed, I.; Baek, S.W.; Waheed, K. Evaporation characteristics of heptane droplets with the addition of aluminum nanoparticles at elevated temperatures. Combust. Flame 2013, 160, 170-183. [CrossRef]

29. Kang, H.; Won, J.; Baek, S.W.; Kwon, S. Autoignition and combustion characteristics of sodium borohydride-based non-toxic hypergolic fuel droplet at elevated temperatures. Combust. Flame 2017, 181, 149-156. [CrossRef]

30. Nachmoni, G.; Natan, B. Combustion characteristics of gel fuels. Combust. Sci. Technol. 2000, 156, $139-157$. [CrossRef]

31. Rah, S.-C.; Sarofim, A.F.; Beer, J.M. Ignition and combustion of liquid fuel droplets part II: Ignition studies. Combust. Sci. Technol. 1986, 49, 169-184. [CrossRef]

32. Qate, M.; Pourabdian, M.; Javareshkian, A.; Farzbod, A. A review of ignition delay and combustion characteristics of biodiesel fueled diesel engine. Appl. Mech. Mater. 2013, 390, 333-337.

33. Wang, C.-H.; Chen, J.-T. An experimental investigation of the burning characteristics of water-oil emulsions. Int. Commun. Heat Mass Transfer 1996, 23, 823-834. [CrossRef]

34. Mishra, D.; Patyal, A. Effects of initial droplet diameter and pressure on burning of atf gel propellant droplets. Fuel 2012, 95, 226-233. [CrossRef]

35. Lee, A.; Law, C.K. An experimental investigation on the vaporization and combustion of methanol and ethanol droplets. Combust. Sci. Technol. 1992, 86, 253-265. [CrossRef]

36. Botero, M.; Huang, Y.; Zhu, D.; Molina, A.; Law, C. Synergistic combustion of droplets of ethanol, diesel and biodiesel mixtures. Fuel 2012, 94, 342-347. [CrossRef] 